\title{
Innovations in the Management of E-Commerce: Analysis of Customer Interactions during the COVID-19 Pandemic
}

\author{
František Pollák ${ }^{1, *}$,, Michal Konečný ${ }^{1}$ and Deniss Ščeulovs ${ }^{2}$ \\ 1 Faculty of Corporate Strategy, Institute of Technology and Business in České Budějovice, Nemanická 436/7, \\ 37010 České Budějovice, Czech Republic; michal.konecny@mail.vstecb.cz \\ 2 Faculty of Engineering Economics and Management, Riga Technical University, Kalnciema Street 6, \\ Room 408, LV-1048 Riga, Latvia; deniss.sceulovs@rtu.lv \\ * Correspondence: frantisek.pollak@mail.vstecb.cz
}

\section{check for}

updates

Citation: Pollák, F.; Konečný, M.; Ščeulovs, D. Innovations in the Management of E-Commerce: Analysis of Customer Interactions during the COVID-19 Pandemic. Sustainability 2021, 13, 7986. https://doi.org/10.3390/su13147986

Academic Editors: JinHyo Joseph Yun, Yuri Sadoi, Valentina Della Corte, JungHyun Yoon and Wookjoon Sung

Received: 30 June 2021

Accepted: 15 July 2021

Published: 16 July 2021

Publisher's Note: MDPI stays neutral with regard to jurisdictional claims in published maps and institutional affiliations.

Copyright: (c) 2021 by the authors. Licensee MDPI, Basel, Switzerland. This article is an open access article distributed under the terms and conditions of the Creative Commons Attribution (CC BY) license (https:/ / creativecommons.org/licenses/by/ $4.0 /)$.

\begin{abstract}
In the days leading to the outbreak of the COVID-19 pandemic, open innovations in the form of the deployment of digital marketing tools in the management portfolio were an option; in a time of forced closing of economies, they suddenly became a necessity. The aim of the comprehensive research, in which the presented study is prepared, is to describe the changes in e-consumer behavior that occurred in the market during the COVID-19 pandemic. The presented study examines the seasonal and regional specifics that characterize the markets of Central and Eastern Europe. In a sample of almost 14,000,000 Facebook users, the user interactions with ten selected representatives of the e-commerce sector were recorded daily during the 2020/2021 Christmas season lasting 49 days. By analyzing the nature and timing of interactions, it was possible to identify the geographical specifics of e-consumer behavior, as well as basic seasonality indicators based on a comparison with the reference period of the first half of 2020. The synthesis of the findings provided a knowledge base for compiling a preliminary version of the model of the COVID-19 pandemic impact on e-consumer behavior. In terms of changes in e-consumer behavior, it can be stated that the step change in ebehavior patterns caused by the pandemic merges with pre-pandemic behavior patterns. In general, it can be stated that the evolutionary process of the transition from offline to online the COVID-19 pandemic appears to be a significant acceleration factor of inevitable changes.
\end{abstract}

Keywords: innovation; management; e-shop; social network; facebook; pandemic; e-consumer behavior; Czech Republic; Latvia; regional development

\section{Introduction}

This research is based on two assumptions. The first assumption, or rather the foundation of management sciences, is a statement that innovation is one of the basic functions of business [1,2]. The second assumption is the continuity of changes in the market. Under the pressure of continuous change in the global market, commercial companies are exposed to considerable business risk. Having the right product does not automatically ensure market success. Achieving a competitive advantage at a low price is only possible in certain specific areas of production. Traditional communication channels face their physical limitations. The last domain of standardized marketing in the form of proximity to the customer, in the sense of brick-and-mortar stores as the place where business transactions were predominantly executed, is also endangered by the changes related to the COVID-19 pandemic. At the time of their advent, information technologies gave e-business pioneers a significant competitive advantage [3-5]. Businesses benefited both from shortening communication channels and optimizing business processes. A by-product of deploying e-business tools in business was information, which represented a significant competitive advantage for companies [6]. Internally, information help optimize production, and externally, it optimizes a full range of tools used to build relationship with customers. From the point of view of the key representatives from the ranks of companies, 
the situation on the global market, as well as on local markets, has stabilized with the onset of the new millennium. The need to deploy IT tools has been saturated. The absence of information technologies in terms of their direct integration into business concerned only a specific part of entities, almost exclusively falling into the category of small and medium-sized enterprises. It is an objective fact that technology alone does not guarantee market success [7]. Effective use of information and communication technologies is a key factor in determining competitiveness of all companies, regardless of their size.

The market turmoil caused by the unexpected onset of a new coronavirus pandemic in the first months of 2020 has largely tested the entire digital infrastructure, and the fact that it was the whole digital infrastructure best describes the complexity of the situation. Within the European market, there were only a few countries that did not close their traditional infrastructure, at least temporarily. However, it was not just about Europe, but the patterns of crisis behavior were predominantly global in nature. The response of consumers was immediate, in the first moment the response manifested itself in the form of a sudden accumulation of stocks [8]. Subsequently, by saturating basic needs and initially eliminating perceived threats arising from a possible shortage of commodities, consumers have approached the digitization of processes to procure most of their needs, including food [9]. Due to the absence of traditional infrastructure, the dominant rate of interactions has been digitized. It was both the digitization of simple interactions replacing the physical interactions of people, and the digitization of most key processes ensuring the functioning of the consumer society.

A considerable part of our research efforts focused on the description of the fundamental parameters of changes and circumstances during the previous fifteen months. From the point of view of scientific research, we focused on the studies by [10-12] on the development of an empirical knowledge base for the description of basic changes in the consumer behavior of Central Europeans.

We proceeded from the assumption that the national closure of economies in the first half of 2020, in terms of its duration and scope, have significantly changed the usual patterns of consumer behavior, specifically consumer behavior in the online space of Czechs and Slovaks.

However, in addition to empirical data, we also identified fundamental limitations related to seasonality and possible geographical specificity. To remove these limitations, we have formulated the following research question:

How is the geographical specificity of the region a determining factor in e-customer behavior?

To answer this question, it was necessary to make a comparison of the reference markets. Based on the assumption that geographically close units show similar characteristics [13], we looked for a reference market that would show certain features of cultural compatibility, but at the same time would correspond to a defined parameter of geographical specificity. The Baltic market was chosen for comparison, with a special focus on Latvia.

To consider the other limitation of the original research, we have chosen the period of the Christmas season 2020/2021 as the reference period. It traditionally begins on Black Friday and ends in the first week of the new year. Within this 49-day period, the interactions of millions of Facebook users with the official profiles of the main representatives of ecommerce for both the Czech and Latvian markets were monitored on a daily basis.

The results of the analyses complement our previous studies and create a holistic picture of 2020 in terms of changes in e-consumer behavior caused by measures to mitigate the spread of the COVID-19 pandemic in Central and Eastern Europe.

As for the structure of the study, the chapter Theoretical Framework deals with both the issue of e-commerce and the specifics of selected markets. Subsequently, we will present the objectives and methods of the study, which will be followed by a chapter presenting the evaluation of the results of the analysis. The findings will be the subject of a thorough discussion. In the end, we will evaluate the entire research in its holistic form throughout the year 2020. 


\section{Theoretical Framework}

Within the theoretical overview, we will gradually describe the current state of knowledge in the issue. The first part of the overview will describe the basic determinants of the issue in terms of using technology as a generator of competitive advantage. In the second part, the overview will focus on describing the analyzed market in terms of its regional specifics. The third part of the chapter will deal with the description of consumer behavior specifics in the environment of social networks. By analysis and subsequent synthesis of knowledge, it will be possible to specify the basic starting points for research.

\subsection{Open Innovations and Information Technology as a Source of Competitive Advantage}

The impact of open innovation on business competitiveness is unprecedented. Whether it is the direct application of information and communication technologies in business, or the application of technology as a business of various entities. Kristapsone and Bruna [14] state that technology companies are at the forefront of today's most valuable companies. However, profit is not just a domain of technology solution providers. Users of these solutions also gain a significant competitive advantage. Bumanis, Vitols, and Arhipova [15] state that there is a wide range of solutions within the market, enabling traders to gain a competitive advantage by actively combining their services with those of their suppliers. As an example, we can mention shopping objects, which are objects automatically generated or created by the user on the basis of a previous transaction. This includes, e.g., payment for a bus ticket, a concert ticket, or travel insurance.

Information technologies are also one of the possible determinants of regional development. Meijere and Tambovceva [7] point to the successful implementation of technological solutions that enable the development of rural areas. In their study, the authors rely on an extensive review of the literature, as well as case studies and their own empirical research. In their work, they state that technological innovations significantly facilitate the development of rural areas, especially in sectors such as e-commerce, healthcare, public services and, finally, in the field of distance education. Digitization, as one aspect of technological innovation, can also be a major accelerator of development. This is also the case for small and medium-sized enterprises. The authors Mokhtar et al. [16] in their study, point to this aspect of the application of technology in business practice. Adopting technological innovation is, of course, a challenge, especially when it comes to an emerging market. Another important area of practical use of innovation to generate benefits is e-governance. Szopinski and Staniewski [17] examined the willingness of the population in the postcommunist countries in the European Union to use e-government services. The authors analyzed the manifestations of the use of electronic administration in a sample of 7984 respondents from Bulgaria, the Czech Republic, Estonia, Lithuania, Latvia, Hungary, Poland, Romania, and Slovakia. Specifically, these included browsing websites operated by public authorities, establishing contacts with public authorities, downloading forms necessary to obtain a public service, sending completed electronic forms to public administration offices, and contacting public authorities to discuss a relevant agenda. In their research, the authors confirmed the existence of a statistically significant relationship between the respondents' place of residence and their tendency to use specific forms of e-government. Van de Walle et al. [18] analyzed the motives that lead citizens not to use eGovernment services. Based on the findings, they state that the unavailability of hardware and the Internet results in non-acceptance of e-government services, which is not surprising. At the same time, however, they add that when it comes to soft factors, such as the comfort factor, its importance is significantly higher than might be expected at first glance. This is also associated with the last of the determinants; the authors state that another important determinant of non-acceptance is a sufficient supply of non-electronic alternatives.

At this point, we come to one of the key findings in the theoretical review of the topic. Specifically, the fact that both physical proximity and a sufficient supply of alternatives in the form of traditional practices play an important role in consumer decision-making, or rather, these factors can be included in the key determinants of e-consumer behavior. Both 
factors were greatly eliminated by the advent of the COVID-19 pandemic. In the following part, we will focus on this topic.

In their work, Gudele and Jekabsone [19] refer to an extensive theoretical review of studies on the positive impact of e-commerce on business. They identify economy, efficiency, and speed as the key factors generating a competitive advantage. Based on their own empirical findings, they state that there are significant differences between entrepreneurs who make full use of e-commerce opportunities and entrepreneurs who do not use these opportunities at all. Rivza et al. [20] argue that, in terms of globalization, the system of e-commerce is generally an important research topic. This topic is increasingly more important, especially for small and medium-sized enterprises. Within the European Union market, small and medium-sized enterprises form the backbone of EU member states national economy. The authors further add that the opportunity for the development of electronic commerce is primarily based on the expansion of digitization, where buyers and sellers meet within the e-environment and their interactions take place without the need for physical contact. This is an advantage for all parties involved.

We agree with Kristapsone and Bruna [14] who see a generally rapid increase in digitization within the global market. Electronic products and electronic information exchange are an essential part of our lives. The rapid advent of the digital economy in industry, finance, services, etc. has enabled more efficient development of goods and services. The digital economy has a significant impact on our lifestyles, be it communication, the cost of disseminating information, and various supporting processes.

Finally, it is necessary to mention the term digital consumers, which, according to Ozol and Rivza [21], is mostly used to refer to the generation of millennials, even if the digital market is not limited to specific generation, as the digital consumers are represented by users across all generations. Digital consumers actively use the full range of innovative tools to support business in the processes associated with consumer behavior. Here, this can be referred to as e-consumer behavior, which is another key concept of the topic being analyzed. The following subchapter deals with a theoretical overview of the regional specifics of the analyzed market.

\subsection{Regional Specifics of the Analyzed Market}

Both the Central European market and the Baltic markets are largely influenced by their common history, which is originated in the times of the planned economy in the second half of the twentieth century. The market conditions of the post-communist countries created specific patterns of behavior [22,23], which were largely similar within the entire Eastern bloc. At this point, it can be discussed how the global digital market creates the conditions for maintaining regional specificities, whether for producers or consumers. Based on empirical studies and e-commerce practice, Guseva [24] argues that in the context of globalization, customers still need to feel connected to culture, vendor of products, or service provider. The author identified and combined the main cultural and psychological aspects influencing e-shopping decisions and found that cultural adaptation has a great potential for improving the effectiveness of communication with customers. In other words, the localization of electronic offers positively influences the dialogue between a seller and a customer. The element of similar culture, in this case based on a common history, thus represents a fundamental integrating factor that allows for the comparison of selected geographical units. At the same time, the principle of choosing cultural compatibility under conditions of geographical specificity is not violated.

Regarding the specificity of individual markets, the Czech e-commerce market shows signs of high development [25-27]. This applies to strong local business players as well as numerous and active digital customer communities. As for the Latvian market, based on the work of Ozola and Rivza [21], we conclude that, in terms of the situation in the commercial and public sectors, Latvian entrepreneurs are still partially reluctant to make full use of e-commerce. This situation is partly due to the lack of knowledge or skills in the field of e-commerce, and the lack of IT specialists. From the point of view of soft factors, 
this is mainly due to a lack of trust in electronic data security. Based on research from the pre-pandemic period, it is possible to point to data from the work of Gudele [28]. The author presents statistical data that show a very low use of e-commerce in the Latvian SME sector. This is especially the case of regional companies.

Gudele and Rivza [29] monitored key factors influencing the development of the Internet and e-commerce within the Baltic countries, analyzing statistics from Estonia, Lithuania, and Latvia. They compared various processes within the economic, political, and social life of these countries over the last 24 years. The authors claim that with the development of infrastructure and information technologies, a completely new business environment has been created. This environment has different rules and creates different opportunities for business development. A new environment has been created in which new opportunities and new challenges have different application potentials in different countries. The authors further argue that the level of well-being in any country influences the adaptation to the new business environment, use of technology, and the habits of the population. It is thus possible to state that the better the economic situation in a given country, the more active its population and its business environment are within the new virtual market. These are objective preconditions for fulfilling the condition of regional specificity.

\subsection{E-Consumer Behavior in the Context of Virtual Social Networks}

The phenomenon of social networks and their gradual integration into the traditional marketing mix have been observed for more than a decade. There has also been a relatively significant interest of the scientific community in research into the use of social networks to support entrepreneurship. The following literary research focuses on the authors who consider the geographical aspect mentioned in our study. Sceulovs and Gaile-Sarkane [30] state that social networks represent the most popular electronic tool of communication. Even though this statement was postulated ten years ago, its topicality and its validity remain up to date. Additionally, the increasingly better prospect, despite the apparent saturation of the market just before the outbreak of the global pandemic, has not changed significantly for ten years. The topic is gaining in importance, especially in the context of retail. Linina, Bruksle, and Zvirgzdina [31] state that retail plays an important role in the state economy, as the relationship between the customer and the company is created within the business. Both parties find benefit from this relationship. The goal of companies is to maximize benefits in the form of increased turnover and, of course, profit. Customer goals are much more diverse. The interactivity of social networks creates an ideal precondition for reaching the goals of both stakeholders.

However, the issue also has a certain degree of limitations which must be taken into account. As for customers, there is the awareness aspect to be considered. In their study, Casno, Skiltre, and Sloka [32] confirmed a statistically significant positive relationship between the level of consumer awareness and their shopping behavior. It is thus necessary to take a consistent approach to considering both the level of knowledge and digital competencies of customers, as well as their preferences concerning current trends $[33,34]$. Regarding the limitations on the side of companies, there are more important facts to be considered. Batraga et al. [35] argue that modern consumers can now choose from a huge range of products and services when making purchasing decisions. This increases competition. Companies need to find new ways and more effective communication measures to successfully influence consumers' decision-making. However, without relevant data and a thorough analysis, it is necessary to accept a considerable degree of uncertainty when predicting future consumer behavior. This is also one of the reasons why the results of e-consumer behavior research should be an important part of the management decisionmaking process in every business. Radionova-Girsa and Praude [36] focus on sellers who started operating online. According to the authors, they faced a challenge of transferring all their acquired knowledge and practice to the online environment. It is no longer possible to use traditional approaches only, as the act of buying as the most important moment in 
the process of consumer behavior in the online environment is very different from buying in bricks-and-mortar shops. Gaitniece, Batraga, and Viksne [37] mention specific studies on consumer behavior, which point to the fact that consumers are spending more and more time online. At the same time, they take into account the information they obtain directly via the Internet for their purchasing decisions.

Batraga et al. [35] state that by applying specific procedures, it is possible to define relatively precisely the expected activities of the consumer. It is also possible to predict sales volumes, revenues, turnover and, finally, to predict the development potential of a company. This is especially the case during periods when sales reach high levels, such as during the holidays. Last but not least, there is the element of trust; Al-Adwan and Kokash [38] states that trust, specifically the trust in a social networking site, has positive influence on purchase intentions of customers. Moreover, trust encourages information seeking, which in turn improves their purchase intentions. Consumer behavior is thus influenced, not only by products, perceptions of brand values, and the effectiveness of marketing communication, but also by cultural, social, individual, and psychological factors. By synthesizing the findings, it is possible to point out the high application potential of social media as a tool to support business.

\subsection{Starting Points for Research on e-Consumer Behavior in the Context of the COVID-19 Pandemic}

As described above, stakeholders maximize their benefits through their interactions in digital ecosystem environments, such as Facebook virtual communities. Through their online activities, companies can better stimulate sales and optimize processes, but mainly increase their competitive advantage over their online passive competitors [39-41]. Customers maximize their benefits by actively searching for products that best meet their needs [42,43]. Meeting these needs can be both quantitative and qualitative in nature. The main cost to the consumer (of course, apart from the direct financial resources spent) is, in the case of maximizing the benefits of online shopping, time. The efficient use of this resource often meets the limits of the structured form of a working day.

At this point, we come directly to the essence of our research efforts over the last fifteen months [10-12,43]. We perceive the optimization of processes related to the effective timing of marketing activities of business entities in the context of our research into the impact of the COVID-19 pandemic on e-consumer behavior as key, as the constraints related to the attempts to slow down the pandemic in 2020 (in the form of sudden closure of economies) have caused significant changes in traditional patterns of consumer behavior. The question of how permanent these changes are, now, is currently impossible to answer. Thus, the research challenge is the need to examine the specific changes in e-consumer behavior caused by the new coronavirus pandemic. This research problem was decomposed from the point of view of the feasibility of its solution both in the context of the specific market of selected Central and Eastern European countries and in the time context of the effects of the pandemic. Two research questions were formulated within the topic as follows:

Has there been a change in the interactions between companies and their customer communities during the current week?

Has there been a change in the interactions of companies and their customer communities during the current day?

As already mentioned in the introduction, these questions were partially addressed in previous studies [10-12,43], and certain limitations were identified that need to be removed. Seasonality and geographical specificity are the determinants that need to be considered when creating an empirical model of the pandemic effects on e-consumer behavior. From the point of view of the timing of research phases (described in more detail in the figure below), a total of five procedural steps/stages of research were identified, within which the research topic will be addressed to answer the research questions.

The presented study comprises Phase 4, i.e., the pre-final step of creating the model while aiming to answer the following research question:

How is the geographical specificity of the region a determining factor in e-customer behavior? 
As we can see in Figure 1, the final step in creating the model is conditioned by answering this research question; it is also a prerequisite for answering the question of the permanence of changes in e-consumer behavior, which is the subject of the fifth, currently ongoing phase of research. The process of collecting empirical material of Phase 5 was completed at the beginning of June, data from the dataset are currently being evaluated.

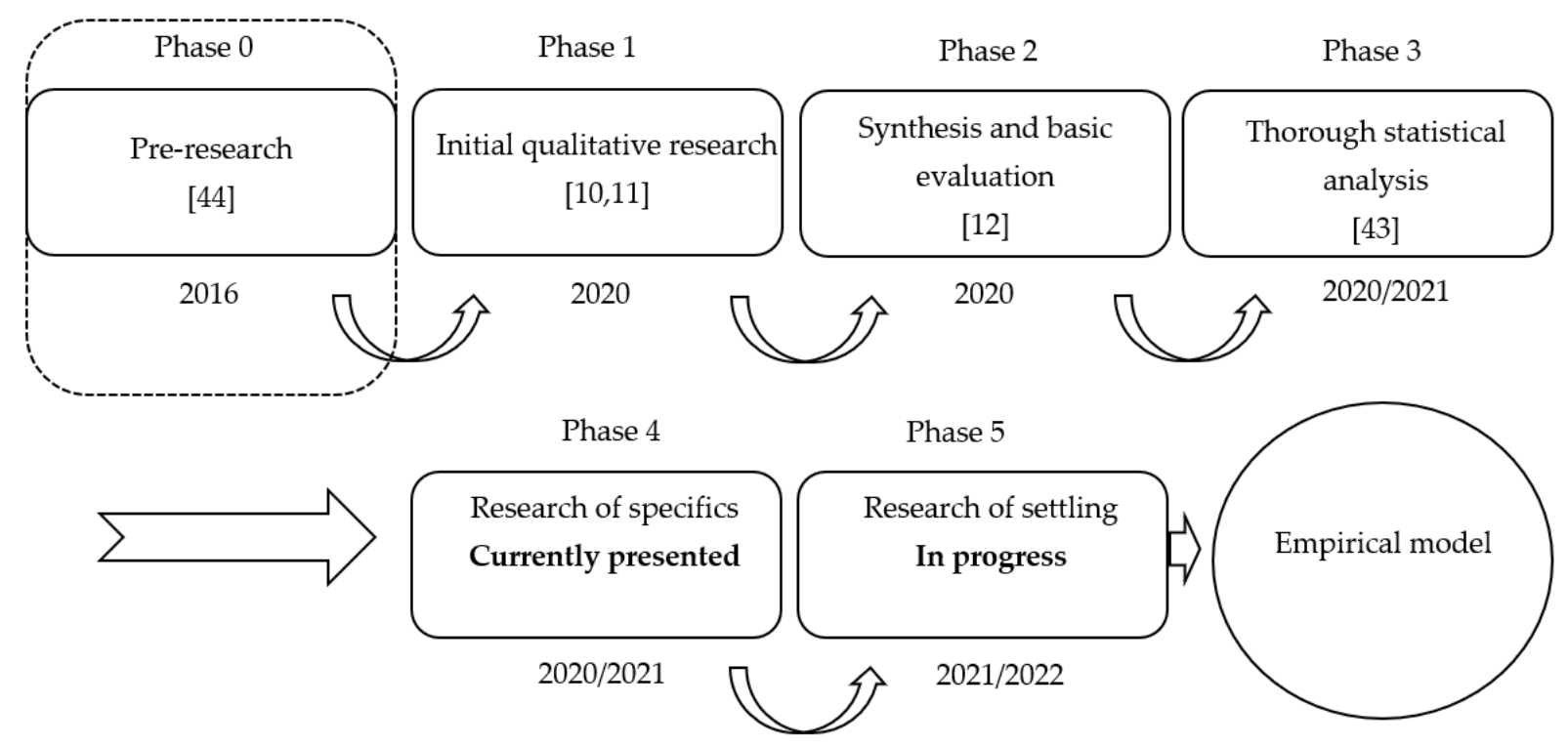

Figure 1. Timing of research phases.

As seen in the figure, the research was preceded by a study [44], which defined the basic parameters of the following research. The study examined the extent to which it is possible to quantify basic indicators of activity on social networks from the user's point of view.

From the point of view of the findings, the basic characteristics of e-consumer behavior of customers on social networks were described. From the point of view of interactions on their marketing communication, the profiles of business companies recorded a relatively balanced number of customer interactions both during a normal day and during a normal week. Mild maxima were recorded in the early evening hours of the current day and also at the end of the current week. Examining and basic description of the timing of the initial variables created a knowledge base for subsequent design of the currently implemented research. As the research subject is significantly different, this step is referred to as Phase 0 in the figure.

The next, but in fact the initial phase of the current research (Phase 1) has a form of gathering the basic empirical material obtained by analysis performed on a significant sample of e-commerce representatives operating in the selected market. At the same time, we created an extensive overview of the state of knowledge based on the available literature. From the point of view of the literature, the basic changes in the market, which were caused by the onset of the COVID-19 pandemic, were described. A rather surprising finding was the fact that, regardless of the geographical location, the behavior of market entities was largely identical. The characteristics of crisis behavior obviously do not have a dominantly regional basis. After studying the current state of knowledge, we proceeded to an empirical analysis based on the methodology from Phase 0 . The reference markets of the Czech Republic and Slovakia were monitored throughout the first state of emergency in 2020 in both countries. We noticed significant differences in the e-consumer behavior of Czechs and Slovaks in comparison with the reference Phase 0 . The dominant part of interactions shifted to the working day, where different markets showed changes predominantly in the order of more active days within the working week. To confront the initial findings with 
the feedback from the academic community, the results were presented to the professional public through presentations at international scientific conferences [10,11].

Based on the feedback from the professional public, in Phase 2, we proceeded to the initial processing of the results recorded in the datasets and compared the two analyzed markets, the product of which was the study accepted for publication in a major monograph [12]. Within the chapter entitled Analysis of E-Consumer Behavior During The COVID-19 Pandemic, we performed the initial statistical processing of activity indicators in both geographically close markets. Both markets showed statistically significant changes in the basic activity indicators in terms of changes in the frequencies of these indicators during the working day and during the weekend.

The created knowledge base, as well as the obtained feedback from the professional public, allowed us to translate the idea into a more sophisticated form, and ensured the allocation of the necessary resources for further development of the topic. Using allocated resources, we proceeded to Phase 3, consisting of an in-depth statistical analysis of the identified relationships. The product of this analysis was the study [43], which suggested that, during the pandemic, there was a major reallocation of interactions in terms of their timing. Most interactions take place during the working week. From a day-today perspective, most of the interactions occur at around noon. In view of the findings, it can be stated that, in order to maintain the competitiveness resulting from efficient management of corporate resources, it will be necessary to modify the usual procedures of e-marketing communication. The results of the study helped identify the key limitations that had been addressed in the paper being submitted. This is also the output of Phase 4 , and an important component for the compilation of the resulting empirical model, as described in the text preceding the figure shown.

After defining the necessary connections, it is then possible to proceed to the description of the material and methods used in the presented study.

\section{Materials and Methods}

As mentioned in previous chapters, the market has undergone a significant transformation under pressure of measures applied to slow down the pandemic of a new coronavirus. These measures have affected almost all areas of life.

The aim of our research is to provide empirical material necessary to create a model of the COVID-19 pandemic impact on e-consumer behavior. The presented study comprises the fourth, i.e., pre-final phase of production of this model, while aiming to answer the following research question:

How is the geographical specificity of the region a determining factor in e-customer behavior?

The main goal of the presented study is to answer the research question, which also removes the main complex limitations of research identified based on feedback from the general public during almost fifteen months of continuous research within Phases 1-3 (see the figure above). To answer the research question, it is necessary to consider the following:

The subject of the research is the interaction of a significant sample of e-commerce representatives with their users through official Facebook fan profiles. The social network Facebook was chosen as a platform representing the place of implementation of consumer interactions, which were moved from the offline to the online environment under the pressure of pandemic measures. In the global market, the social network Facebook is the dominant platform with almost three billion active users, so for the purposes of our research it represents a rational choice.

The Czech market is represented by the five largest entities ranked by the e-commerce bridge portal [45] based on their website traffic, namely:

- Alza.cz;

- Mall.cz;

- CZC.cz;

- Aukro.cz;

- $\quad$ Lidl Czech Republic. 
From the perspective of the cumulative number of users within the selected entities' fan base, this is an extensive customer base. These collectives have almost two million active local users, i.e., both actual and potential customers of the subjects.

The reference Latvian market is represented by five e-commerce players ranked by the glopal.com platform [46]. Based on the specifics of the market, there are also large international platforms among national players. Specifically, these are the following entities:

- Ss.lv;

- 1a.lv;

- Amazon.de;

- Ebay.co.uk;

- Amazon.co.uk.

The first and second positions are occupied by local entities; however, in the third position, first specificity of the market can be noticed. A specificity of the Latvian market is that the dominant part of customers uses international platforms for their e-commerce activities. This fact was partly described in the theoretical overview, where we pointed out the fact that, in terms of e-commerce in Latvia, it is still a young emerging market. From the point of view of users, this phenomenon is quite interesting. In contrast to the Czech market, we work in this case with only 150,000 locals (Ss.lv and 1a.lv) but also with more than 12,000,000 global (Amazon and eBay) representatives of customer groups.

As part of the comparison carried out in Phase 3, we compare selected characteristics of the initial state, which are represented by interactions recorded during the 67 days of the first state of emergency declared in the Czech Republic (March to May 2020). In Phase 4, this situation is compared with the subsequent partial closure of the Czech economy during the Christmas holidays at the turn of 2020 and 2021 (seasonal reference period of 49 days). The aim is to remove the limitation in the form of seasonality. In parallel, we compare the characteristics recorded during the Christmas period in the Czech Republic and Latvia to remove the limitation in the form of geographical specificity.

In the monitored period, user-base interactions with official profiles of e-commerce entities in the form of their fan pages were recorded daily. In terms of interactions, the following parameters were recorded:

- Number of published posts;

- User response to published posts in the form of: (i) like; (ii) share; and (iii) comment.

From the point of view of monitored parameters, both the frequency and timing of individual interactions were monitored. As for time, the intervals were in the form of the days of a working week. From the day perspective, the time intervals were divided as follows:

- 00:00-08:00;

- 08:00-12:00;

- 12:00-16:00;

- 16:00-20:0;

- 20:00-00:00.

Records were read at a predefined time interval so that the theoretical maximum values of individual interactions could be reached. Given the technology available, it was not possible to record the exact time of each individual interaction (except for the timing of contributions). Interactions in the form of like, share, and comment were subtracted by indirect extrapolation from the times of the contributions to which they applied. We proceeded from the assumption that the dominant part of the interactions occurs immediately at the time of publishing the content.

Due to the research phase and the extent of necessary data processing, we used descriptive statistics tools for subsequent data processing, except for the first dataset, in which we tested the data distribution across the working week and weekends using the Mann-Whitney and Kolmogorov-Smirnov tests. This testing was necessary to correctly define the parameters for comparing seasonality and regional specificity. 
The findings presented in the following chapter provide us with an empirical knowledge base for answering the primary research question, which in its decomposed form clarifies the following:

- During the first closure of the economy in the Czech Republic, was there a significant difference in the timing of interactions during the working week and the weekend?

- Is it possible to identify the difference in the timing of interactions recorded during the first closure of the economy in the Czech Republic and the subsequent partial closure of the economy during the Christmas holidays?

- Is it possible to identify differences in the e-consumer behavior of users in the Czech Republic and Latvia on the basis of recorded interactions during the Christmas period?

- Is seasonality a significant determinant of e-consumer behavior?

- Is market specificity a significant determinant of e-consumer behavior?

After the specification of the material and research methods, it is possible to proceed to the presentation and subsequent discussion of the results of our empirical research.

\section{Results and Discussion}

The results of our empirical research are divided into three logically consecutive parts.

The first part presents the initial state representing the first lockdown in 2020 declared during the state of emergency in the Czech Republic. The key links are subject to statistical investigation. The findings are interpreted through a summary table.

The second part has a form of a presentation of the results of the study on the next partial closure of the economy during the Christmas holidays 2020/2021 in the Czech Republic.

The third part reflects the same period and presents the results of the reference market survey in Latvia.

The interpretation of the findings is followed by a preliminary draft of the working version of the model and an extensive discussion of the results in order to describe the key context, the phenomenon of seasonality, and the specificity of individual markets.

\subsection{Baseline_First Lockdown (March to May 2020, Czech Republic)}

The lockdown in the Czech Republic, which represented the period of declared first state of emergency (March to May 2020), was more than non-standard. If we take into account the unprecedentedness of the situation, we must also adopt the postulate of a considerable degree of uncertainty in all areas and processes taking place in the country. This state represents Phase 1 of our research. As part of the initial considerations on the design of the research, setting goals, subject, and specifying the sample, we followed up on the research from 2016 [44]. The analysis of the available data helped us to outline the expected patterns of e-consumer behavior in the pre-crisis period. I It can be stated that, with regard to the standard behavior of social network users before the outbreak of the pandemic, user activity is distributed approximately evenly within a business day, while a slight increase in activity can be observed in the early evening. From the point of view of activity within a working week, the situation with an approximately even distribution of the monitored parameters is repeated, a slight increase in the monitored parameters is recorded on Monday and subsequently with at the beginning of the weekend.

Regarding the changes in e-behavior caused by measures related to the attempt to slow down the spread of the new coronavirus pandemic in the spring of 2020 in the Czech Republic, extensive empirical data collection took place in the first phase of our study as described in the previous chapter of the presented study. In Phases 2 and 3, a series of surveys were conducted, which allowed us to confirm the hypothesis of the statistical significance of changes in e-behavior, i.e., in the number of interactions recorded on working days and weekends during the lockdown. In terms of the monitored parameters, we record a slightly increased number of comments during the working week, but it does not show any signs of statistical significance. In contrast, all other monitored parameters, i.e., comments, sharing, and likes, reach significantly higher values during the working week compared to the weekend. From the point of view of moment characteristics, we 
notice statistically significant differences in most cases. The null hypotheses of the MannWhitney test and the Kolmogorov-Smirnov test are rejected at the significance level $\alpha=0.05$ for all monitored parameters, except the comments, as follows in Table 1:

Table 1. Statistical comparison of moment characteristics. Source: [43].

\begin{tabular}{ccccc}
\hline & Like & Comment & Share & Post \\
\hline $\begin{array}{c}\text { Median comparison } \\
\begin{array}{c}\text { Distribution function } \\
\text { comparison }\end{array}\end{array}$ & $\mathrm{U}=348^{*}$ & $\mathrm{U}=438$ & $291.5^{* *}$ & $\mathrm{U}=53^{* *}$ \\
\hline * Indicates significance level at 0.05 level. ${ }^{* *}$ Indicates significance level at 0.01 level. & & $\mathrm{KS}=3.433^{* *}$
\end{tabular}

E-consumer communities represented by the user bases of the Facebook profiles of the main e-commerce industry representatives in the Czech Republic maximized their benefits during the forced closure of the economy by increasing their activity in the digital environment. Customers achieved the direct benefit by participating in the marketing activities of e-commerce entities, which usually take form of (i) competitions (maximizing the benefits in terms of the possibility of free product procurement); (ii) discounts (maximizing the benefits in terms of financial resources saved when purchasing a product in exchange for online activity); and (iii) raising awareness (achieving benefits in terms of better/more complex satisfaction of needs). Businesses maximized their benefits in terms of increased turnover, with e-commerce being almost the only way to procure most consumer goods (excluding basic consumer products). They also obtained valuable information and feedback, the analysis of which created the preconditions for a significant increase in competitiveness.

Thus, a thorough statistical analysis enabled answering the first of the decomposed research questions as follows:

During the first closure of the economy in the Czech Republic, there was a significant difference in the timing of most interactions during the working week and the weekend.

It is thus possible to continue an analysis of seasonality and geographical specificity.

\subsection{Analysis of Seasonality (Christmas Season 2020/2021, Czech Republic)}

Unlike the first, the second closure of the economy at the turn of 2020 and 2021 was partly expected. However, the Christmas closure has caused a considerably serious situation on the market, characterized by increasing resistance to restrictions on the side of both companies and customers. The partial assimilation of market entities to the pandemic situation put pressure on the authorities; in the monitored period under review, we reject the postulate of the exclusivity of e-commerce in terms of the possibility of procuring (other than necessary) products. We assumed that the patterns of behavior created during the first lockdown would partially persist, as the conditions for maximizing the benefits of all parties to the market had not changed. The following Figure 2 compares the initial characteristics of e-consumer behavior of Czechs during the first and second lockdown as follows:

Before interpreting the findings, it is necessary to define the initial activity indicators for both monitored periods. During the first lockdown, average cumulative numbers were calculated based on the user communities' behavior, consisting of 1,594,180 users in total. For 67 days, they generated 901,760 interactions on 689 posts published on official Facebook profiles of selected e-commerce entities. The ratio of interactions per contribution in this case was 1308:1.

Regarding the Christmas season, during the monitored period of 49 days, 1,807,085 users made 678,820 interactions concerning a total of 575 posts published on official Facebook profiles of selected e-commerce entities. The ratio of interactions per contribution in this case dropped to $1180: 1$. 


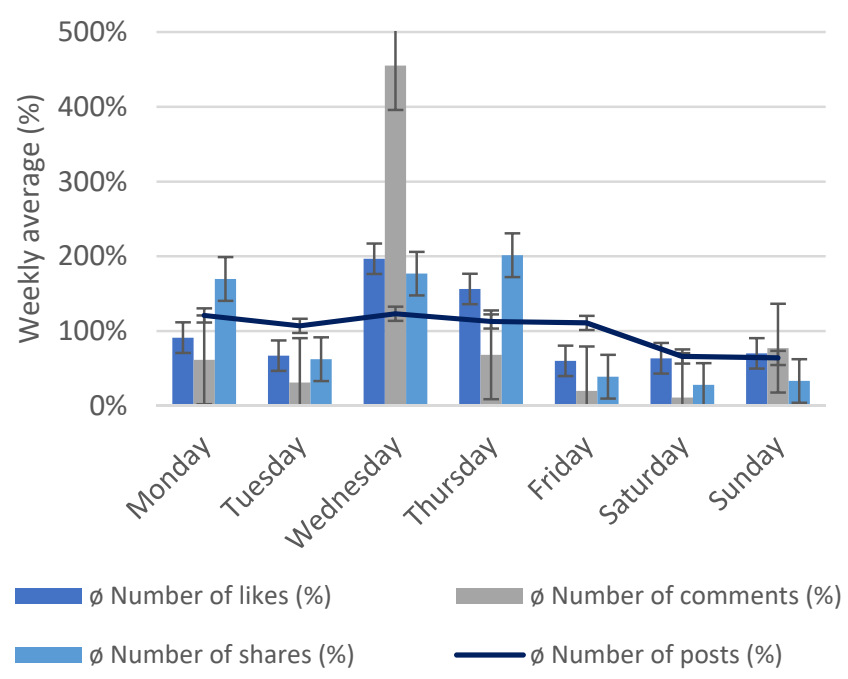

(a)

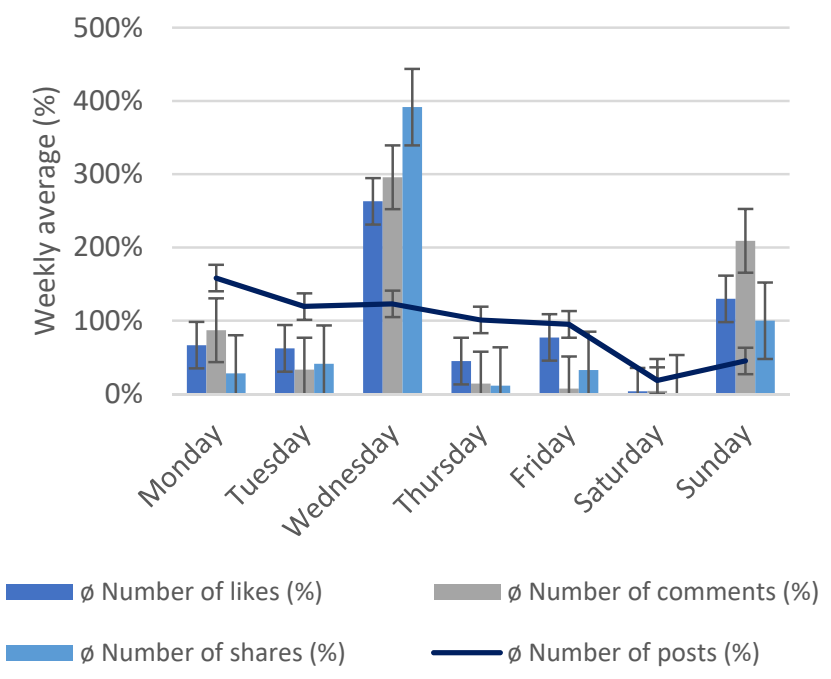

(b)

Figure 2. Histogram of interactions-model week in Czech Republic. (a) Average cumulative values of interactions during the model week (March to May 2020); (b) Average cumulative values of interactions during the model week (Christmas season 2020/2021).

Based on a comparison of the initial activity indicator, i.e., the ratio of the average number of interactions per contribution, we can see a significant decrease in user activity during the second closure of the economy in the Czech Republic. Namely, it is a decrease of more than $10 \%$. This fact also confirms the assumption that the conditions of the second lockdown were significantly different, which resulted from the adaptation of entities to the crisis situation. The available data show that in the middle of the week, the number of interactions culminated again, regardless of their nature. However, there are several specific differences compared to the first lockdown, namely: (i) the decrease in the average cumulative number of interactions during working days (excluding Wednesday) below the average cumulative weekly values; (ii) the return of Sunday as the second most active day in terms of the model week (at this point, we note the assumption that customers satisfy their weekend online needs mostly on Sunday); and (iii) a decrease in the activity indicator between the first and second lockdowns from 1308:1 to 1180:1.

For a holistic description of the situation, we consider it essential to present data pointing to the distribution of interactions within predefined time intervals during a business day. Based on the processed datasets, the data can be presented via histograms as follows in Figure 3:

As for the interactions within the predefined sections of the model working day and the model weekend day, there are changes in selected monitored parameters within the two monitored periods. Due to the ongoing in-depth analysis of the context, the interpretations are predominantly descriptive. Nevertheless, it is possible to deduce from the histograms that, during the second lockdown, there was a certain confirmation of changes in e-consumer behavior from the point of view of acquired habits. While in the first observation, we can see that the time when most users satisfied their digital needs was between 8.00-12:00, and subsequently a stabilization of interactions at their average levels until the evening, in the second lockdown, the digital needs were satisfied relatively constantly throughout the working day. At the same time, we observe a significant attenuation of interactions during the hours within personal free time by default. We evaluate this fact, and the trend identified from it, as a significant negative from the point of view of work efficiency during a working day, especially if this phenomenon occurs during the planned work from home. As for the weekend, the dominant part of digital needs is satisfied in the morning, but even here we are seeing a partial return to pre-crisis behavior in the form of an increase in interactions in the evening hours. 

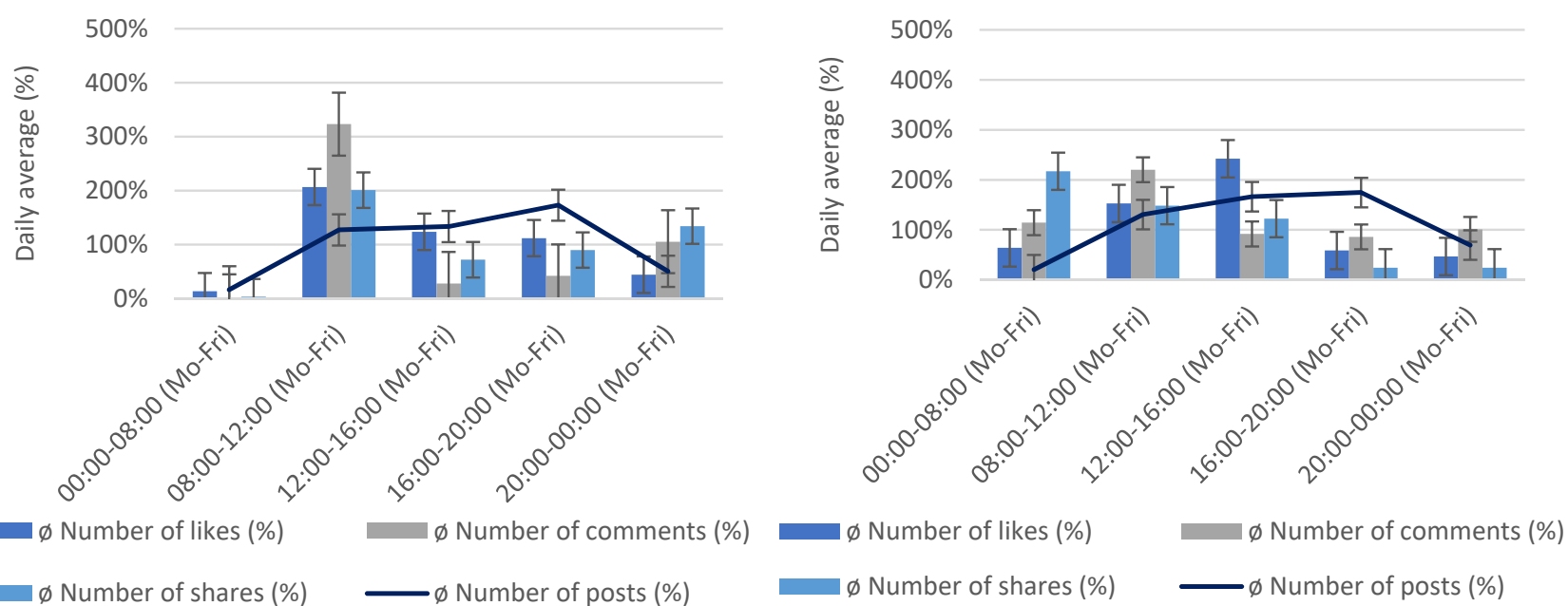

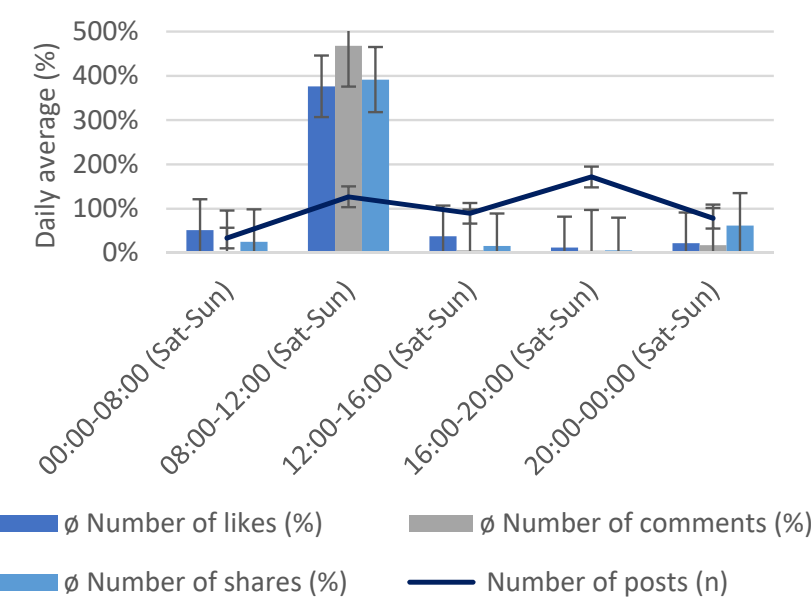

(a)

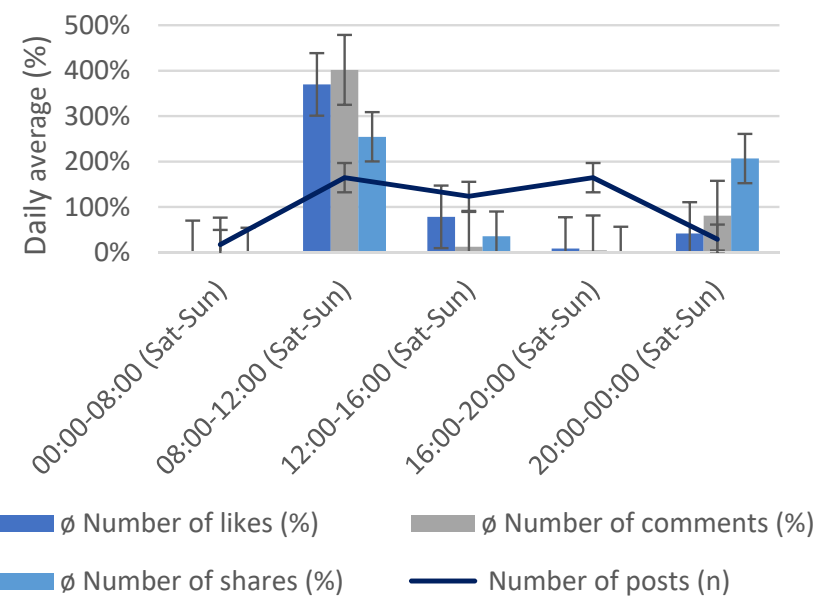

(b)

Figure 3. Histogram of interactions-model day in Czech Republic. (a) Average cumulative values of interactions during the model day (March to May 2020); (b) Average cumulative values of interactions during the model day (Christmas season 2020/2021).

Based on the interpreted findings, the second of the decomposed research questions can be answered as follows:

It is possible to identify the difference in the timing of interactions recorded during the first closure of the economy in the Czech Republic and the subsequent partial closure of the economy during the Christmas holidays.

At this point, we proceed to the analysis of geographical specificity.

\subsection{Analysis of Market Specificity (Christmas Season 2020/2021, Latvia)}

As for the Latvian e-commerce market, we encounter relatively different elements, both in terms of activity and in the composition of the entities operating in the market. In terms of market size represented by the number of inhabitants in the country, the Latvian market represents about one-fifth of the market of the Czech Republic. We have taken this limiting factor into account, as the indicators of online activity are presented in cumulative relative frequencies, the assumption of mutual comparison of data is sufficiently observed.

Based on the findings presented in the theoretical overview, we assumed that the analyzed market would show some specific parameters. The authors [28,29] addressing the issue describe the market as catching up or developing. They also mention the considerable market asymmetry at the regional level. This fact was confirmed in the initial phase of the research, where we recorded quite surprising findings. Based on relevant sources of knowledge [46], we identified five main players operating in the local e-commerce 
market, while only two of them are located directly on the Latvian market, so they can be identified as domestic. The remaining entities represent two global players, namely eBay and Amazon, with Amazon being preferred by Latvian users in both English and German modification.

In the next step, we came across another specificity, based on the relatively evolving nature of the market compared to the Czech Republic. Specifically, we came across the fact that both the first and the second Local Entity (the first and second entities in terms of the most preferred e-commerce entities operating in the Latvian market), despite the hundreds of thousands of cumulative fan base on official Facebook profiles, develop almost no e-marketing efforts towards user groups (tribes). This confirms another theoretical assumption [21], pointing to the relatively weak online activity of Latvian businesses on the Internet. We will thus formulate our findings based on a dataset working with the data on the online activity of two global players, Amazon and eBay, with Amazon representing both Amazon.de and Amazon.co.uk in the analysis. In total, the interactions of 12,012,745 global users of these e-commerce players are analyzed. Within 49 days, these e-consumer groups produced 83,581 interactions concerning a total of 113 posts published on the official Facebook profiles of the mentioned entities. From the point of view of the basic indicator of activity, the ratio of interactions to one contribution, we record the value of 739: 1. This value accounts for more than $60 \%$ of the value of the activity indicator of the Czech e-commerce market in the same period. This finding also points to the fact that when it comes to e-commerce, the Czech market achieves highly above-average values. These values are achieved both in terms of e-marketing activity of e-commerce entities and in terms of the activity of user tribes of their customers. The following visualization in Figure 4 compares the basic characteristics of e-consumer behavior of Czechs and Latvians (Latvians users are extrapolated on the assumption of similarity from the behavior of all users of global Amazon and eBay profiles).

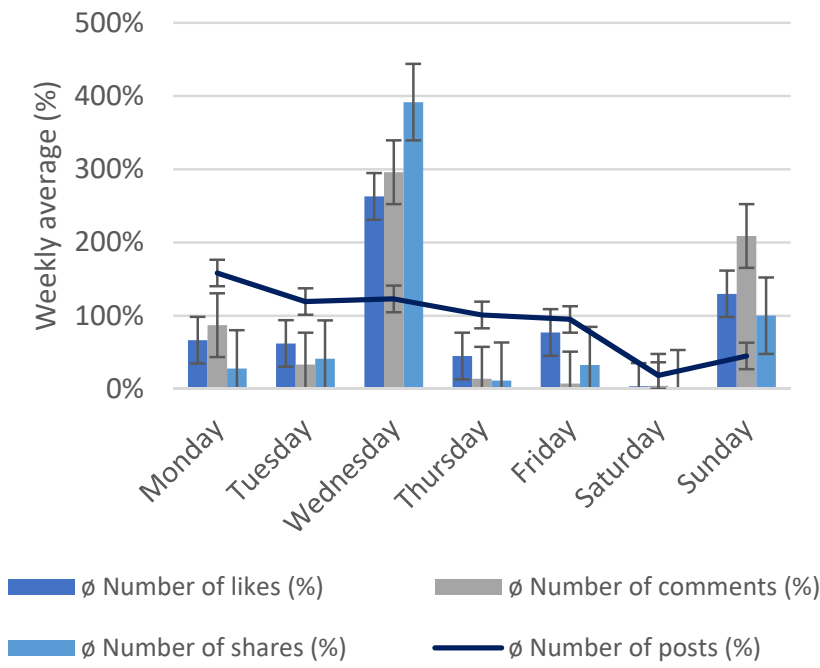

(a)
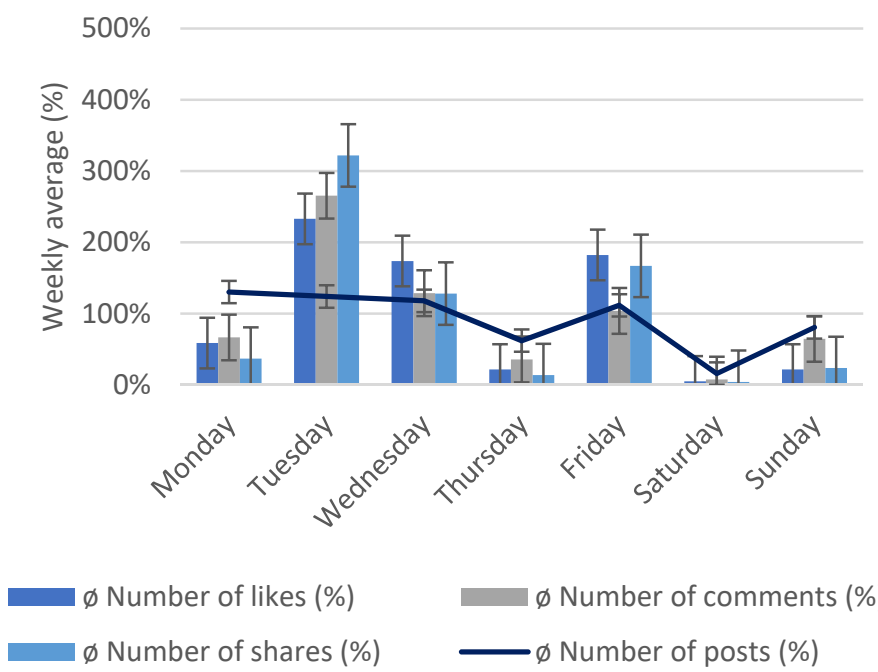

$\varnothing$ Number of comments (\%) $\longrightarrow$ Number of posts (\%)

(b)

Figure 4. Histogram of interactions-model week in Czech Republic vs. model week in Latvia. (a) Average cumulative values of interactions during the model week (Christmas season 2020/2021 in Czech Republic); (b) Average cumulative values of interactions during the model week (Christmas season 2020/2021 in Latvia).

In the compared markets, we can observe a similar trend in terms of the timing of e-marketing activities on the profiles of e-commerce entities. We also observe relatively similar characteristics of e-consumer behavior on Monday and Saturday. Compared to the Czech market, entities operating on the Latvian market record maximum number of interactions with their userbases more evenly during the working week with a relatively slight increase at the end of the weekend. Without a deeper analysis, it could be assumed 
that both businesses and users maximize their benefits in the same way as their Czech neighbors. However, this is not the case. The differences are shown in the following histogram in Figure 5:
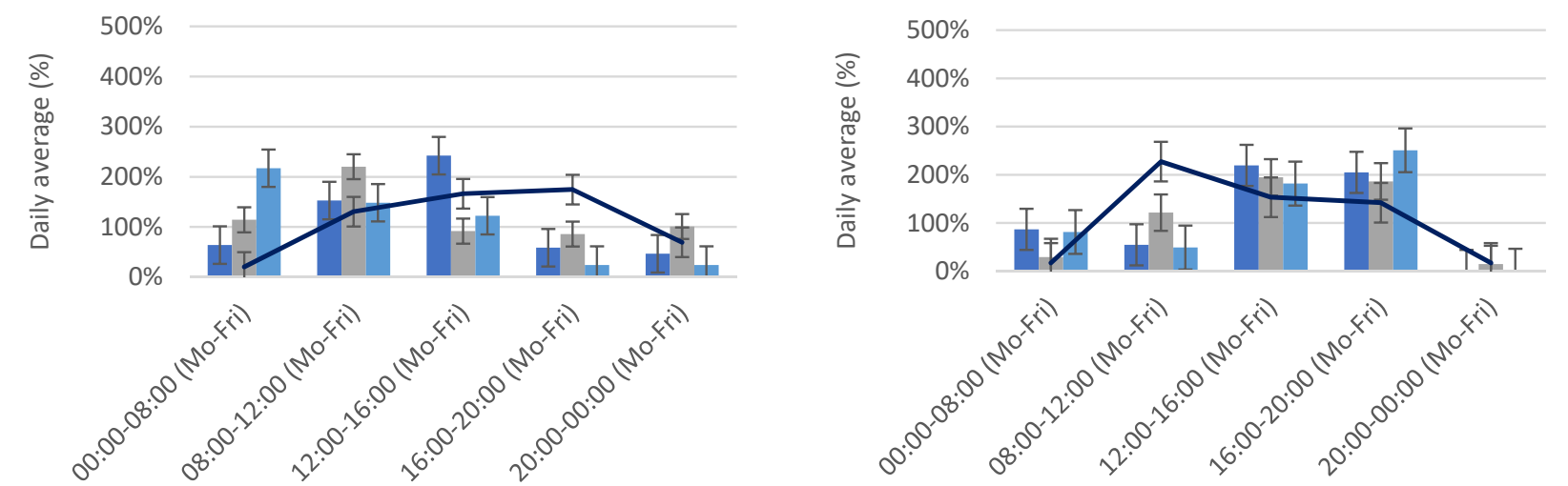

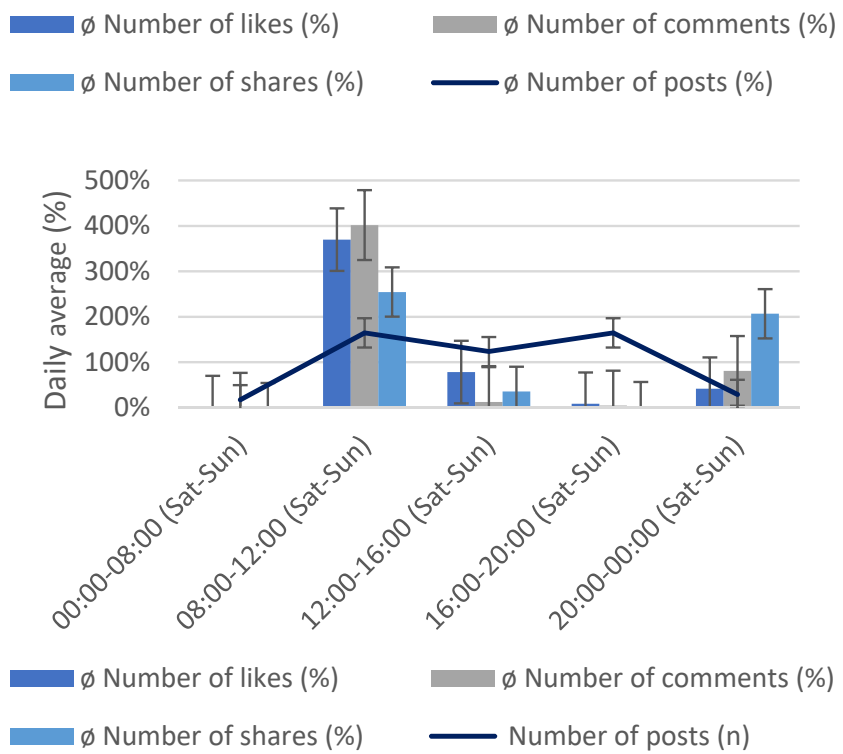

(a)

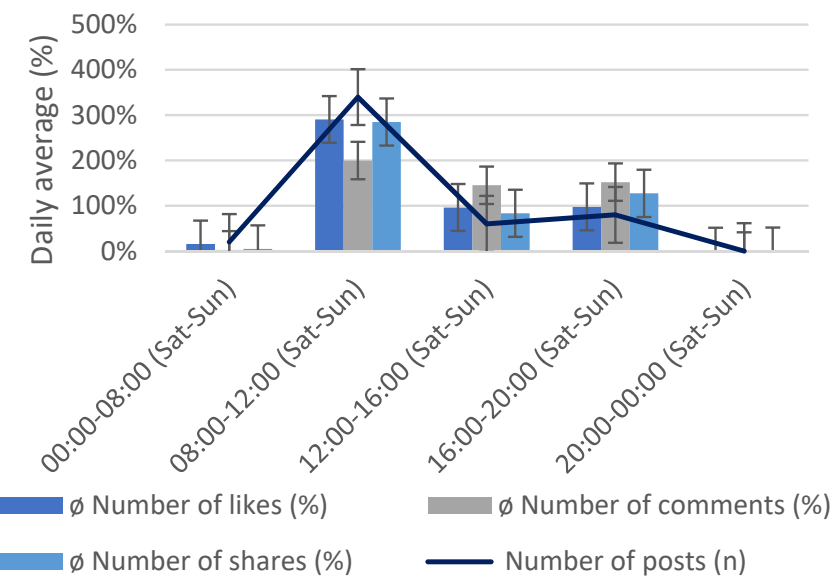

(b)

Figure 5. Histogram of interactions-model day in Czech Republic vs. model day in Latvia. (a) Average cumulative values of interactions during the model day (Christmas season 2020/2021 in Czech Republic); (b) Average cumulative values of interactions during the model day (Christmas season 2020/2021 in Latvia).

From the point of view of interactions within the predefined sections of the model working day and the model weekend day, we noticed significant changes in the monitored parameters within both analyzed markets. If e-consumer behavior in the Czech Republic during the working days is characterized by above-average number of interactions in the form of likes, sharing, or comments, userbases of e-commerce entities preferred on the Latvian market maximize the satisfaction of their digital needs dominantly during the afternoon to evening hours. As for the weekend, users of both monitored markets show relatively similar patterns of e-consumer behavior in the first half of the day; the difference occurs only in the second half of the weekend, where the Czechs increase their online activity in the evening, while users of Amazon and eBay oscillate in the afternoon and the early evening around the average values, where their online activity falls sharply in the evening.

Based on the interpreted findings, the third of the decomposed research questions can be answered as follows. 
It is possible to identify differences in e-consumer behavior of users of the Czech Republic and Latvia based on recorded interactions during the Christmas period.

This is especially true in terms of the timing of interactions during the working day and at the weekend. Both monitored markets show a considerable degree of specificity.

Based on the described characteristics supplemented by the knowledge accumulated in the research phases $1-3$, it is possible to proceed to a preliminary version of the model of changes in e-consumer behavior.

\subsection{Outlining the Preliminary Model}

Based on the findings of the previous research effort, it can be stated that the empirical material enables answering the last two decomposed sub-questions. Both seasonality and market specificity largely determine e-consumer behavior. This makes it possible to answer the primary research question, as based on the findings, it can be stated that the geographical specificity of the region is an important determinant of e-consumer behavior. Considering the data from the zero, pre-research phase, it is necessary to take into account the aspect of the persistence of changes (currently analyzed in Phase 5 of the research) for proposing the final version of the model. This is the only way to assess whether the SARS-CoV-2 pandemic was a black swan for the market, a revolutionary determinant transforming the market into a completely new form, or an evolutionary accelerator of the necessary transition from offline to online.

A preliminary model of the effects of a pandemic on e-consumer behavior can be visualized in Figure 6 as follows:

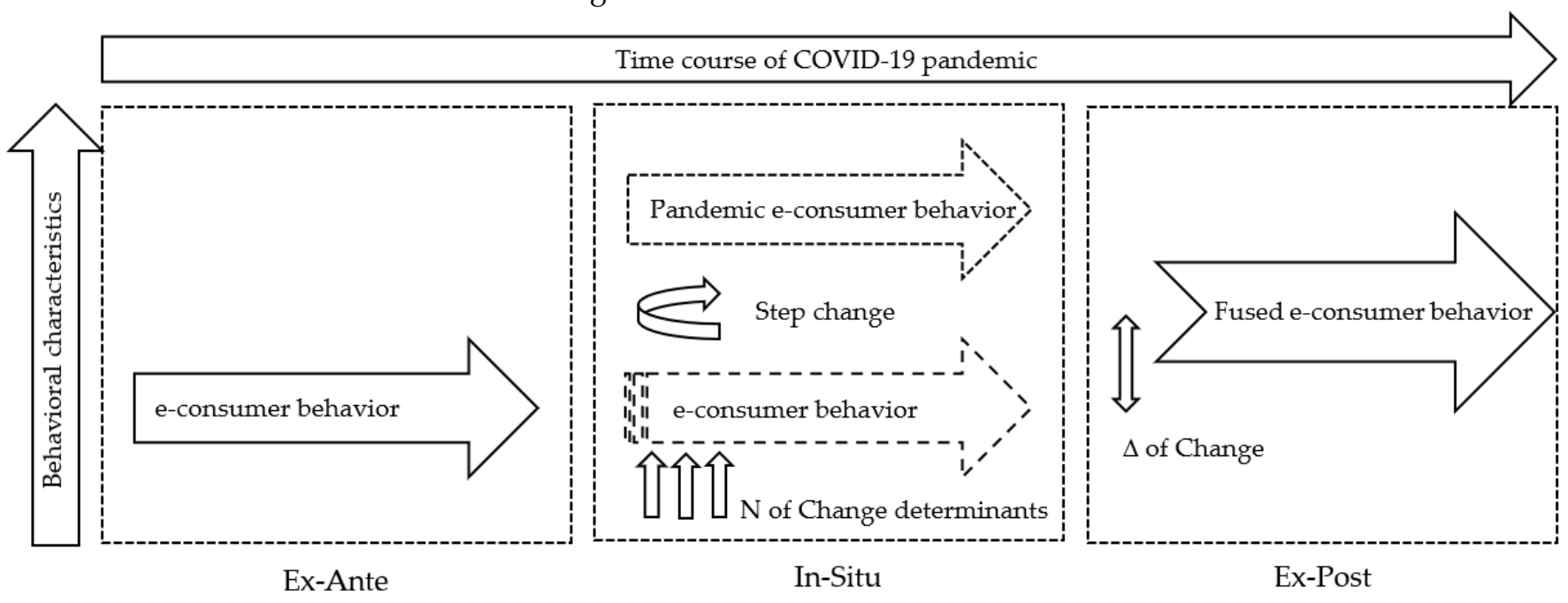

Figure 6. Preliminary model of the impact of the COVID-19 pandemic on e-consumer behavior.

In the Ex-Ante phase, i.e., a state prior to the onset of a pandemic caused by COVID19, e-consumer behavior undergoes a continuous change. However, it has the nature of continuous evolution. Based on the findings so far, we conclude that these evolutionary changes cannot be observed in the short term. Now at the outbreak of the pandemic (in our model referred to as In-Situ), a sharp change in e-consumer behavior was noticed compared to the pre-crisis state [44]. At the same time, we try to identify selected determinants of the change, as well as the influence of individual determinants on change in the characteristics of behavior. In the post-pandemic phase (mentioned in our Ex-Post model), we assume that there will be a fusion of pre-pandemic and pandemic patterns of behavior, where we aim to define both the time necessary for this fusion and the difference between the situation after the fusion and the initial state (in the model, this is referred to $\Delta$ ). We realize that it is not possible to clearly describe all changes in all markets. We thus extrapolate the empirical model based on induction, where we determine the general thesis after examining selected significant cases, from individual to general. 
By describing a preliminary working version of the empirical model, it is possible to discuss the general findings.

\subsection{Discussion}

In the discussion, the main specifics of the analyzed markets will be evaluated. In the conclusion, we will summarize the individual findings by answering both the main and five decomposed research questions.

As for the Czech market, we can confirm the theoretical assumptions [25-27] regarding the nature and activity of the market. It is a complex and active e-commerce market with strong local players (except for Lidl, which is a global player, however, is fully localized for the Czech market). The strength of these businesses is underpinned by the expansion efforts of these businesses to (but not only) Central European markets. From the point of view of domestic customers, we also record considerable market vitality. It can be stated that customers actively participate in the e-marketing activities of profile managers of selected e-commerce entities. The activity rate expressed by the ratio of interactions per unit of e-marketing activity (published contribution on the official Facebook profile of the e-commerce entity) culminates during the first wave and then declines slightly during the second closure of the economy, but the ratio of 1180:1 exceeds the activity rate on global e-commerce market leaders (two versions of Amazon and one version of eBay) expressed by means of the same indicator by almost $40 \%$ during the same reporting period. Finally, we note that the Czech e-commerce market is clearly growing. Between the first and second wave of the pandemic, we record a cumulative increase in the users of the communities of the monitored e-commerce entities from the initial 1,594,180 to 1,807,085. In less than half a year, we have seen an increase in customer groups of more than $12 \%$. Looking at the changes in the e-consumer behavior of the Czechs, we can record a change in e-habits applying to all monitored indicators. The dominant part of the interactions has shifted to the working week, specifically to the time that can be referred to as working time. The step change in the first closure of the economy created habits that are partly becoming the new standard. Based on the monitored characteristics, it can be concluded that the users have lost shyness in terms of maximizing the benefits of their online activity during working hours. At the same time, they spent their working time predominantly working from home. Based on a descriptive analysis of the data collected during the Christmas season, it is clear that Czech users devote a significant part of their working day to maximizing the benefits of e-commerce. This time it is already evenly distributed throughout the working day. There is another phenomenon, namely the fact that certain characteristics of e-consumer behavior are returning to pre-crisis states. During the Christmas season, we notice a gradual increase in interactions at the end of the week, when users mostly satisfy their digital needs. It can be assumed that there is a fusion of pre-crisis and crisis patterns of behavior. However, due to the research phase, this assumption cannot be confirmed.

As for the Latvian market, even in this case, we can confirm the assumptions identified in the theoretical overview [28,29]. The Latvian market is characterized by a significant degree of catching up compared to the market in the Czech Republic. We believe that this is especially due to the size of the market, where this Baltic market, in terms of population/customers, represents less than $20 \%$ of the market in the Czech Republic. We rely on the assumption that a larger market generates a higher synergy of the involved entities, thus achieving a significant acceleration in terms of development. As for the main players preferred by Latvian users in their e-commerce market, the first two positions are occupied by local players. Although the number of their users in the social network environment exceeds 150,000 , the entities pay almost no attention to working with this community. The top five players are complemented by global leaders in the e-commerce industry, namely Amazon (in two language versions) and eBay. The communities of these entities are considerably more passive compared to their Czech counterparts, both in terms of e-commerce activity of the entities themselves and in terms of customer strain interactions. In comparison with the basic indicator of activity in terms of the average 
number of interactions per one published contribution, these entities reach values at the level of $60 \%$ of the values measured in the same period on the Czech market. Regarding the distribution of interactions during a working current week, at first glance it can be stated that the values roughly copy the trends identified on the Czech market. However, upon a more detailed examination of interactions in terms of distribution within the predefined sections of a business day, we find that if the Czech user shows a dominant rate of interactions in the morning, users of e-commerce entities popular in the Latvian market satisfy their digital needs mostly in the afternoon and early evening. Based on this fact, it can be argued that the strict restrictions related to measures to slow down the pandemic in the Czech Republic have contributed to the emergence of such different characteristics in e-consumer behavior.

As for the common features of both markets, we see a penetration in the timing parameter of individual interactions during the weekend. Both monitored customer groups implement the dominant part of their weekend interactions with e-commerce entities in the morning.

We will therefore proceed to a general assessment of the results by discussing the main findings from the perspective of the issue of innovation in the context of market changes caused by the COVID-19 pandemic.

As stated in the introduction of the study, companies are exposed to significant business risk under the pressure of continuous changes in the global market. Product, price, or promotion as the cornerstones of a marketing portfolio, have been restricted by the limitations of the physical world for a long time. However, there were still products that benefited from the tradition and the relative stability of the consumer behavior patterns of their consumers. However, this has also ended. Under the pressures of measures adopted to slow down the spread of the new coronavirus pandemic $[8,9,27]$, consumers have been forced to significantly reduce their physical activity. It was possible to watch as the market went from offline to online. Being close to the customer no longer meant being close to him physically, which, of course, does not mean that the element of proximity has lost its importance $[43,47]$. Customers have transferred much of their activities to the digital world. Virtual communities have become a space for socialization in the time of social distancing [38]. As science evolves, management professionals, both academics and experts from practice, are constantly looking for innovative ways to optimize processes with the aim of achieving the competitive advantage. In this case, the optimization also took place in real time, with the supply side of the market adapting relatively quickly to the new conditions. Both sides of the market were looking for ways to maximize their benefits even more. The supply side maximized the turnover primarily, and subsequently aggregated a relatively large volume of user information. The demand side maximized its benefits in the form of seeking higher value and satisfaction rates. The price for maximizing the benefits was the time that this process necessarily required. However, during the closure of the economy, time was largely an available variable. The study summarizes and presents the level of knowledge that has accumulated over almost fifteen months. Despite considerable efforts, it is not yet the final product of the research, as some of the research parameters are currently in the process of in-depth analysis. The interpretations are thus predominantly based on descriptive processing which, in our opinion, does not compromise importance and value of the findings; on the contrary, it points to the topicality of the issue, at the same time providing insight into the development of the topic over time (apart from the production of knowledge suitable for further research). With this statement, we also close the discussion of the results, and continue with the summarization of findings by answering both the main research question and the five decomposed research sub-questions in the conclusion of the presented study.

\section{Conclusions}

The presented study aims to remove the main limitations of the comprehensive research carried out by answering the research question in its decomposed parts. In the 
first decomposed sub-question, we confirmed that during the first closure of the economy in the Czech Republic, a significant difference was recorded in the timing of interactions during the working week and the weekend. Users started to carry out the dominant part of their interactions during the working week. We believe that this phenomenon occurred naturally and was a rationalized response to changing working conditions. Users thus maximized their benefits from e-commerce while using the time fund for this activity outside the time allocated to their personal time off. We also identified some differences in the timing of interactions recorded during the first closure of the economy in the Czech Republic and the subsequent partial closure of the economy during the Christmas holidays. These took form of a distribution of online activities throughout the working day. Here, we observed the stabilization of newly acquired habits and the transition from sudden to gradual behavior. Regarding the differences in the e-consumer behavior of the users of the Czech Republic and Latvia based on the recorded interactions during the Christmas season, there were several interesting findings. From the point of view of the working week, the customer's e-commerce entities popular on the Latvian market do not show significantly changed characteristics compared to the Czech Republic. However, if we look at the data in more detail, we find that the patterns of behavior are similar within days as such, but in terms of the timing of interactions, user behavior in the analyzed markets is diametrically different. While Czech users maximize the dominant rate of their e-commerce benefit in the morning during the working week, the users in the reference market do so mainly in the afternoon and early evening. This finding is essential to answer the third decomposed sub-question. Regarding the fourth decomposed sub-question, it can be stated that seasonality is a significant determinant of e-consumer behavior. In the Czech market, we can see the stability of certain parameters, but especially the return to satisfying digital needs at the end of the weekend. This brings us to the last partial finding, namely the specificity of the market as a significant determinant of e-consumer behavior. We point out that the e-commerce market in Latvia differs significantly from the market in the Czech Republic. Much of the digital needs of its users are satisfied by multinational entities. These create an affordable alternative to the ever-evolving domestic market. The e-consumer behavior of Latvian users is thus largely globalized, while the Czech market remains predominantly regional, showing both strong domestic supply and strong domestic demand. With this statement, we arrive at the answer to the primary research question in its complex form. Based on the findings, it can be stated that the geographical specificity of the region is a determining factor in e-customer behavior. For different geographical units, it is thus necessary to take into account the national specifics of consumers in e-commerce research. Although the Internet is a global medium, its users maintain a certain degree of regional specificity, regardless of the elimination of a significant number of physical barriers. This fact also points to the need for a continuous analysis of the subject matter. Our research efforts thus primarily take the form of generating knowledge for both science and business practice.

\section{Research Limitations and Direction for Future Research}

The presented study aimed at removing the identified limitations of the third phase of comprehensive research in terms of data seasonality and regional specificity of markets. Despite the considerable efforts of the authors, it can be stated that the submitted study still has some limitations, which result predominantly from the nature of the data, as well as the stage of their processing. The data are (despite extensive datasets) of a dominant qualitative nature. Regarding the stage of their processing, the current study presents the results of the pre-final phase of the production of the empirical model, as described in the previous chapters. Part of the data (Phase 1-3) were thoroughly statistically evaluated, on the basis of which it was possible to end Phase 3 and proceed to research aimed at removing the identified limitations in Phase 4 . The removal of these limitations was based on descriptive data processing. In the final Phase 5, the data necessary for the compilation 
of the empirical model will be tested, which will enable removing one of the last limitations to our research task.

Author Contributions: Conceptualization, F.P. Data curation, F.P.; Formal analysis, F.P.; Funding acquisition, F.P.; Investigation, M.K. and D.Š.; Methodology, F.P.; Project administration, F.P.; Resources, F.P.; Software, F.P.; Supervision, F.P.; Validation, F.P.; Visualization, M.K. and D.Š.; Writing-original draft, M.K. and D.Š.; Writing-review \& editing, F.P. The authors participated in the research topic and share joint responsibility for this work. All authors have read and agreed to the published version of the manuscript.

Funding: This research was funded by the Slovak Republic scientific grant agency VEGA, grant number $1 / 0140 / 21$.

Institutional Review Board Statement: Not applicable.

Informed Consent Statement: Not applicable.

Data Availability Statement: The data presented in this study are an integral part of various project outputs which are openly available on the official project web site [https://www.interreg-central.eu/ Content.Node/ENTER-transfer.html] (accessed on 16 July 2021).

Acknowledgments: We wish to thank all participating project partners for their work in the project and for the materials provided. This contribution is prepared within the project CE1158 ENTERtransfer "Advancement of the economic and social innovation through the creation of the environment enabling business succession".

Conflicts of Interest: The authors declare no conflict of interest.

\section{References}

1. Yun, J.J.; Yigitcanlar, T. Open Innovation in Value Chain for Sustainability of Firms. Sustainability 2017, 9, 811. [CrossRef]

2. Dunska, M.; Salkovska, J.; Batraga, A.; Braslina, L. Consumer Behaviour in Innovative Products Purchasing Process. Mark. Manag. Innov. 2018, 3, 276-289. [CrossRef]

3. Yun, J.J.; Zhao, X. Business Model Innovation through A Rectangular Compass: From the Perspective of Open Innovation with Mechanism Design. J. Open Innov. Technol. Mark. Complex. 2020, 6, 131. [CrossRef]

4. Lee, M.; Yun, J.J.; Pyka, A.; Won, D.; Kodama, F.; Schiuma, G.; Park, H.; Jeon, J.; Park, K.; Jung, K.; et al. How to Respond to the Fourth Industrial Revolution, or the Second Information Technology Revolution? Dynamic New Combinations between Technology, Market, and Society through Open Innovation. J. Open Innov. Technol. Mark. Complex. 2018, 4, 21. [CrossRef]

5. Nambisan, S.; Lyytinen, K.; Majchrzak, A.; Song, M. Digital Innovation Management: Reinventing Innovation Management Research in A Digital World. MIS Q. 2017, 41, 223-238. [CrossRef]

6. Eremina, Y.; Lace, N.; Bistrova, J. Digital Maturity and Corporate Performance: The Case of the Baltic States. J. Open Innov. Technol. Mark. Complex. 2019, 5, 54. [CrossRef]

7. Meijere, S.; Tambovceva, T. Information Communication Technologies as Enabler for Rural Development. In Proceedings of the International Scientific Conference on Economic Science for Rural Development (ESRD), Jelgava, Latvia, 27-28 April 2017; pp. 110-115.

8. Kirk, C.P.; Rifkin, L.S. I'll Trade You Diamonds for Toilet Paper: Consumer Reacting, Coping and Adapting Behaviors in the COVID-19 Pandemic. J. Bus. Res. 2020, 117, 124-131. [CrossRef] [PubMed]

9. Muangmee, C.; Kot, S.; Meekaewkunchorn, N.; Kassakorn, N.; Khalid, B. Factors Determining the Behavioral Intention of Using Food Delivery Apps during COVID-19 Pandemics. J. Theor. Appl. Electron. Commer. Res. 2021, 16, 1297-1310. [CrossRef]

10. Pollák, F.; Konečný, M. Analysis of E-Consumer Behaviour-Selected Findings from An Analysis of Czech E-Shops and Their Customers during the Global Pandemic. SHS Web Conf. 2021, 90, 01015. [CrossRef]

11. Pollák, F.; Malinak, B.; Markovič, P.; Világi, R. Innovations in the Management of E-Commerce Entities Operating on the Slovak Market-Analysis of Customer Interactions during the COVID-19 Pandemic. SHS Web Conf. 2021, 90, 01016. [CrossRef]

12. Pollák, F.; Markovič, P.; Váchal, J.; Vavrek, R. Analysis of E-Consumer Behavior during the COVID-19 Pandemic. In Intelligent Processing and IT tools for E-Commerce Data, Information and Knowledge; Honghao, G., Kim, J.Y., Hussain, W., Eds.; EAI/Springer: Berlin/Heidelberg, Germany, 2021.

13. Lu, Y.; Zhao, L.; Wang, B. From Virtual Community Members to C2C E-Commerce Buyers: Trust in Virtual Communities and Its Effect on Consumers 'Purchase Intention. Electron. Commer. Res. Appl. 2010, 9, 346-360. [CrossRef]

14. Kristapsone, S.; Bruna, S. Indicators of The Information and Communication Technology (ICT) Sector Activity in Latvia and the EU. In Proceedings of the 9th International Scientific Conference on New Challenges of Economic and Business Development-Digital Economy, University of Latvia, Riga, Latvia, 18-20 May 2017; pp. 277-287. 
15. Bumanis, N.; Vitols, G.; Arhipova, I.; Mozga, I. Mobile Ticket Lifecycle Management: Case Study of Public Transport in Latvia. In Proceedings of the 16th International Scientific Conference on Engineering for Rural Development, Jelgava, Latvia, 24-26 May 2017; pp. 82-87.

16. Mokhtar, S.S.S.; Mahomed, A.S.B.; Aziz, Y.A.; Rahman, S.A. Industry 4.0: The Importance of Innovation in Adopting Cloud Computing among Smes in Malaysia. Pol. J. Manag. Stud. 2020, 22, 310-322.

17. Szopinski, T.; Staniewski, M.W. Manifestations of e-Government Usage in Post-Communist European Countries. Internet Res. 2017, 27, 199-210. [CrossRef]

18. Van de Walle, S.; Zeibote, Z.; Stacenko, S.; Muravska, T.; Migchelbrink, K. Explaining Non-Adoption of Electronic Government Services by Citizens: A Study among Non-User of Public E-Services in Latvia. Inf. Polity 2018, 23, 399-409. [CrossRef]

19. Gudele, I.; Jekabsone, I. Factors Contributing to the Development of E-Commerce by the Degree of Use in Latvia. Eur. Integr. Stud. 2020, 14, 207-216.

20. Rivza, B.; Kruzmetra, M.; Rivza, P.; Miceikiene, A.; Balezantis, A.; Jasaitis, J. E-Commerce as A Consequence of Innovation and the Cause of New Innovations for SMEs: The Perspectives of Latvia and Lithuania. Comp. Econ. Res. 2020, 23, 7-20. [CrossRef]

21. Ozola, I.; Rivza, B. Development of Employability Skills in Adult Education. In Proceedings of the 12th Annual International Conference of Education, Research and Innovation (ICERI), Seville, Spain, 11-13 November 2019; pp. 9303-9308.

22. Mishler, W.; Rose, R. Trust, Distrust and Skepticism: Popular Evaluations of Civil and Political Institutions in Post-Communist Societies. J. Politics 1997, 59, 418-451. [CrossRef]

23. Hamm, P.; King, L.P.; Stuckler, D. Mass Privatization, State Capacity, and Economic Growth in Post-Communist Countries. Am. Sociol. Rev. 2012, 77, 295-324. [CrossRef]

24. Guseva, N. Cultural Aspects of Decision-Making in Online Purchases. Mark. Tržište 2013, 25, 8-21.

25. Pilík, M.; Juřičková, E.; Kwarteng, M.A. On-Line Shopping Behaviour in the Czech Republic under the Digital Transformation of Economy. Econ. Ann. XXI 2017, 165, 119-123. [CrossRef]

26. Zaňková, K. Nákupy v Době Koronaviru: Češi Nakupují Fitness Pomůcky Nebo Třeba Domáci Vinotéky, Uvedla Mluvčí. Available online: https:/ / zivotvcesku.cz/nakupy-v-dobe-koronaviru-cesi-nakupuji-fitness-pomucky-nebo-treba-domaci-vinotekyuvedla-mluvci/ (accessed on 16 October 2020).

27. Hambalíková, K. Jak Koronavirus Změnil Nákupní Chování ČECHŮ na Internetu? Available online: https:/ / www.gopay.com/ blog/jak-koronavirus-zmenil-nakupni-chovani-cechu-na-internetu/ (accessed on 17 March 2020).

28. Gudele, I. Usage of AHP Method for Evaluation of E-Commerce Tools for Distance Learning for SME in Latvia. In Proceedings of the 10th Annual International Conference of Education, Research and Innovation (ICERI), Seville, Spain, 16-18 November 2017; pp. 8934-8939.

29. Gudele, I.; Rivza, B. Factors Influencing E-Commerce Development in Baltic Rural Areas. In Proceedings of the 25th NJF Congress on Nordic View to Sustainable Rural Development, Riga, Latvia, 16-18 June 2015; pp. 496-500.

30. Sceulovs, D.; Gaile-Sarkane, E. Social Internet Networks Using for Entrepreneurship's Competitiveness Increasing: Case of Latvia. In Proceedings of the International Conference on Social Sciences and Society (ICSSS 2011), Shanghai, China, 14-15 October 2011; pp. 357-362.

31. Linina, I.; Bruksle, I.; Zvirgzdina, R. Price Discounts as A Goods Promotion Factor in Latvian Retail Trade. In Proceedings of the 20th International Scientific Conference on Economic Science for Rural Development (ESRD), Jelgava, Latvia, 9-10 May 2019; pp. 298-305.

32. Casno, K.; Skiltere, D.; Sloka, B. Factors that Motivate Latvian Consumers to Purchase Products and Services from Social Enterprises in Latvia: The Case of Socially Responsible Consumption. Eur. Integr. Stud. 2019, 13, 90-99. [CrossRef]

33. Tambovceva, T.; Dimante, D.; Atstaja, D. Consumer Behaviour Change through Education for Sustainable Development: Case of Latvia. Int. J. Environ. Technol. Manag. 2018, 21, 238-252. [CrossRef]

34. Bormane, S. Price as An Integrated Marketing Communication Tool in Promoting the Consumption of Sustainable Products. In Proceedings of the CBU International Conference on Innovations in Science and Education, CBU Research Institute, Prague, Czech Republic, 21-23 March 2018; pp. 62-68.

35. Batraga, A.; Salkovska, J.; Legzdina, A.; Rukers, I.; Bormane, S. Consumer Behavior Affecting Factors Leading to Increased Competitiveness During Holiday Season. In Proceedings of the 19th International Scientific Conference on Economic Science for Rural Development (ESRD), Jelgava, Latvia, 9-11 May 2018; pp. 329-337.

36. Radionova-Girsa, E.; Praude, V. Doing Business on The Internet: Dealing with Online Customers in Latvia. In Proceedings of the 10th International Scientific Conference on New Challenges of Economic and Business Development-Productivity and Economic Growth, Riga, Latvia, 10-12 May 2018; pp. 532-539.

37. Gaitniece, E.; Batraga, A.; Viksne, K. eWOM Factors Influence on Consumer Decision Journey. In Proceedings of the 9th International Scientific Conference on New Challenges of Economic and Business Development-Digital Economy, Riga, Latvia, 18-20 May 2017; pp. 215-223.

38. Al-Adwan, A.S.; Kokash, H. The Driving Forces of Facebook Social Commerce. J. Theor. Appl. Electron. Commer. Res. 2019, 14, 15-32. [CrossRef]

39. Nosratabadi, S.; Mosavi, A.; Shamshirband, S.; Kazimieras Zavadskas, E.; Rakotonirainy, A.; Chau, K.W. Sustainable Business Models: A Review. Sustainability 2019, 11, 1663. [CrossRef] 
40. Braojos, J.; Benitez, J.; Llorens, J. How Do Social Commerce-IT Capabilities Influence Firm Performance? Theory and Empirical Evidence. Inf. Manag. 2019, 56, 155-171. [CrossRef]

41. Barroso, R.M.R.; Ferreira, F.A.F.; Meiduté-Kavaliauskiené, I.; Banaitiené, N.; Falcão, P.F.; Rosa, A. Analyzing the Determinants of E-Commerce in Small and Medium-Sized Enterprises: A Cognition-Driven Framework. Technol. Econ. Dev. Econ. 2019, 25, 496-518. [CrossRef]

42. Lv, J.; Wang, Z.; Huang, Y.; Wang, T.; Wang, Y. How Can E-Commerce Businesses Implement Discount Strategies through Social Media? Sustainability 2020, 12, 7459. [CrossRef]

43. Pollák, F.; Vavrek, R.; Váchal, J.; Markovič, P.; Konečný, M. Analysis of Digital Customer Communities in Terms of Their Interactions during the First Wave of the COVID-19 Pandemic. Manag. Marketing. Chall. Knowl. Soc. 2021, 16, 134-151. [CrossRef]

44. Pollák, F.; Dorčák, P. The Effective Use of Facebook by Small and Medium-Sized Enterprises Operating in Slovakia. Mark. Tržište 2016, 28, 79-91.

45. Ecommerce Bridge. The Largest E-Shops in Slovakia and in the World in 2019. Available online: https:/ /www.ecommercebridge. sk/najvacsie-e-shopy/ (accessed on 20 March 2020).

46. Glopal. Selling Online in Latvia. Available online: https://merchants.glopal.com/en-us/sell-online/latvia (accessed on 10 October 2020).

47. Pollák, F; Markovič, P. Economic Activity as A Determinant for Customer Adoption of Social Media Marketing. Sustainability 2021, 13, 3999. [CrossRef] 